\title{
Too busy: why time is a health and environmental problem
}

\author{
Lyndall Strazdins ${ }^{\mathrm{A}, \mathrm{B}}$ and Bernadette Loughrey ${ }^{\mathrm{A}}$ \\ ${ }^{\mathrm{A} N a t i o n a l ~ C e n t r e ~ f o r ~ E p i d e m i o l o g y ~ a n d ~ P o p u l a t i o n ~ H e a l t h, ~}$ \\ The Australian National University \\ BCorresponding author.Email: lyndall.strazdins@anu.edu.au
}

\begin{abstract}
Time pressure is emerging as a modern malaise. It is linked to changes in working life, with longer work hours and faster work pace, and it is compounded in families; nowadays both parents must combine working with caring. Time pressure also challenges urban, health and environmental policy because many interventions have an unacknowledged time dimension. People need time to keep healthy, to exercise and to maintain strong social and family bonds. If urban designs or environmental solutions can reduce time demands they may directly improve health and social outcomes. However, where they increase time demands they may have unanticipated health costs, create disincentives for the uptake of interventions and disadvantage those who are most time poor.
\end{abstract}

Daily exercise and good nutrition could reduce the modern epidemics of obesity, Type 2 diabetes, and heart disease. At the same time, urban environmental problems such as heatwaves and air pollution are related to carbon dioxide emissions and hence car use, which public transport, cycling and walking would help to alleviate. Yet despite the twin benefits for health and the environment less than $5 \%$ of people walk to work each day and only $1 \%$ cycle. Instead, four out of five Australian commuters travel by car. ${ }^{1}$

Why hasn't behaviour change occurred on anything like the scale required? How can policy respond to these public health and environmental threats? We argue that current solutions often have an unacknowledged time dimension, one vital factor constraining their uptake. The availability of free time has declined, and if interventions are to succeed they must avoid adding to time burdens. Like income, time is a resource. It is limited and has become more precious because of changes in the nature of work, how long people are working, who is working and the time costs of care. This paper briefly reviews why time pressure has become so widespread, who is most affected and the likely time consequences of the ageing population.

\section{Work intensification}

One hundred and fifty years ago, long work hours were a feature of the Australian economy. It was not until 1856 that an eight hour day became a right, at least for a few. Work hours did not reduce immediately (in 1890 they still averaged over 50 hours a week), ${ }^{2}$ nor did they change for all employees, but average hours gradually declined until the early 1980s, when Australian full-time workers averaged less than 40 hours per week. ${ }^{3}$ The decade of the 1970 s marked a turning point. Global competition accelerated because of widespread financial deregulation, the strengthening of global economic institutions (e.g. the World Trade Organization and the International Monetary Fund), the growth in multinational corporations and international movement of capital. Some public sector services were downsized or privatised and businesses began competing much more in global markets. As a result, flexible and insecure employment increased in many developed economies. ${ }^{4}$ In Australia, employees began to work longer and harder and average full-time work hours rose. ${ }^{5}$

Currently, one third of the Australian labour force puts in unpaid overtime, ${ }^{6}$ one-third of men in full-time jobs work more than 50 hours a week ${ }^{7}$ and the average Australian full-time employee works nearly 42 hours per week. ${ }^{8}$ But it is not only the number of hours spent at work that generates time pressure. The pace and intensity of work adds to the experience of busyness. Across European nations work intensity has increased for the past 20 years, with more people working harder, at very high speed and under a great deal of tension. ${ }^{9}$ Data for Australia does not cover that whole time span, but what evidence there is indicates similar trends here. 9,10 Technological advances such as laptop computers, email and mobile phones further complicate the boundary between work and free time, adding to the experience of overload.

\section{The reconfiguration of work and family life}

Women are now nearly half of the Australian labour force, and much of this increase has been driven by the workforce participation of mothers. In 2001, over $72 \%$ of Australian mothers with dependent children worked for pay, compared to $46 \%$ of mothers in the $1980 \mathrm{~s} .{ }^{11}$ Even mothers with very young children show a similar trend. In 
$2000,45 \%$ of Australian women with children aged under four were in the paid workforce compared to $29 \%$ in 1985.12

A less visible consequence is the transformation of free time. For families, the combined work times of both parents reveals how much time use has changed. Three decades ago, most couple families in the United States (US) had mothers at home, and in these households the time devoted to paid work (by fathers) averaged 45 hours per week. Now, dual-earner families are the most common family type and in the US the time devoted to paid work (from both parents combined) averages 82 hours per week. ${ }^{13}$ In Australia the figure is lower, closer to 70 hours per week. ${ }^{14}$

Families with employed parents may have more income, but they are now 'time poor', and the pressures of time poverty are especially acute for mothers. Adding together paid and unpaid work, the total time demands on full-time employed parents is 14 hours per day for mothers and 12 hours per day for fathers. ${ }^{15}$ Child care helps but does not solve the problem because parents still strive to preserve time with their children. ${ }^{16}$ What is lost is leisure time. Men and women without children average 35 and 31 hours of leisure time per week respectively, but fathers and mothers of infants (when care demands are high) only average eight hours and two hours per week. ${ }^{15}$ Now, a significant proportion of adults struggle to find time free from working and caring.

\section{Time for health}

Yet, people need time to keep healthy. In an Australian survey on obesity, one in five experts ranked time pressure as the single most important social trend underlying the rising rates of obesity. ${ }^{17}$ Both sedentary and active individuals cited lack of time, ahead of either income or knowledge, as the barrier to regularly exercising. ${ }^{18}$ Similarly, a quarter of Australian women said that exercising five or more times per week was definitely not feasible ${ }^{19}$ and finding time for exercise is especially a problem for mothers. ${ }^{18}$ Preparing nutritious meals also takes time, and in a European survey of 14000 people one third of respondents listed lack of time as a major barrier to healthy eating. ${ }^{20}$ One reason why people eat 'fast food' is to save time.

\section{Travel time}

Time costs also shape travel choices. Two thirds of drivers in Sydney said that they would use public transport if it were as quick as car travel. Time spent waiting for public transport is viewed as particularly wasteful, so both the actual journey time and the waiting time act as disincentives. ${ }^{21}$ Initiatives to increase the use of public transport may not consider the potential compounding time impacts for adults who both work and care. In these time-poor families, daily travel must fit in children's activities alongside parents' work, so walking, cycling or public transport are almost never time-feasible.

\section{The ageing population}

The ageing population could exacerbate time shortages. In 2004, 13\% of Australia's population was aged 65 years and over. In 2051, this is projected to increase to between 26 and $28 \%$. $^{22}$ The consequences are threefold: there will be proportionally fewer working age adults and they will face more pressures to work; the need for elder care will increase; and more people will be combining work with family care. For some households paid work will need to be combined with caring for both children and ageing parents. ${ }^{8}$

\section{Saving time}

The solutions to urgent public health and environmental problems are competing in what is a time-scarce market. Work has intensified and work hours are rising, while demographic trends create acute pressures for adults combining working with caring. Meanwhile the modern epidemics of obesity, diabetes and heart disease are putting pressure on health service costs. The challenge is to design interventions that will succeed.

What are the opportunities for policy makers and urban planners? First, time impact assessments should be part of any design brief, with particular attention given to different demographic groups. Second, time savings should be a goal of each proposed health and environmental intervention and should inform the decision whether to implement the intervention or not. Workplaces, schools, childcare and community centres for elders could be located along a single bus or train route, and there must be more investment in high speed public transport. Where time savings are not possible, creative solutions and cross-sector collaborations will be required. Time trading schemes (like carbon trading) could be considered, underwritten by estimated savings to health services. For example, the US civil rights lawyer, Edgar Cahn, pioneered the notion of time banks in the early 1980s. Under these schemes, time currency is earned for caring or community work. Credit can be used to call on other members' time or on goods and services like public transport and refurbished computers. ${ }^{23}$ Perhaps tax incentives could be offered to businesses that curb long working hours similar to the tax deductions provided for research and development expenditure. Policy makers, planners and corporate leaders should also advocate for a culture of time awareness, and cost-benefit analyses ought to include time as well as money. Meanwhile awards and publicity could be given to businesses that make time and workload allowances so their employees can use public transport or exercise during the work day.

Why not tackle time? Maybe the issues seem too hard or too complex, outside the usual authority of environmental 
and public health policy. It is not certain, for example, if time savings in one domain (such as travel) would result in spending more time on exercise or preparing healthy food. Indeed some travel researchers argue that time allocations are quite fixed so that increasing transport speed simply leads to more trips or traveling greater distances (see Schaefer and Victor, ${ }^{24}$ and for a counter view Mokhtarian and $\mathrm{Chen}^{25}$ ). Perhaps, because the problem of time has not yet been solved, people assume it can never be solved. On the other hand, there is a market for anything that can save time; holidays, services, technologies and even medication advertisements are already tapping it. Solutions to health and environmental problems, if they are to be feasible and widely embraced, need to capture this market too. Otherwise simply adding to time burdens could inadvertently penalise the nation's productive, caring and regenerative base, making it even harder to achieve public health and environmental goals.

\section{Acknowledgements}

We thank Dorothy Broom, Tony Capon and Jane Dixon for their comments and help with earlier drafts, and Tessa McDonald for her input on policy strategies.

\section{References}

1. Flood M, Barbato C. Off to work: commuting in Australia. Canberra: The Australia Institute, 2005.

2. Australian Bureau of Statistics. Australian Social Trends 1995. Canberra: ABS, 1995.

3. Australian Bureau of Statistics. Labour Force Historical Summary: 1966-1984. Canberra: ABS, 1985.

4. Organisation for Economic Co-operation and Development (OECD). OECD employment outlook 2007. Paris: OECD, 2007.

5. Quiggin J. Globalisation, neoliberalism and inequality in Australia. ELRRev 1999; 10(2): 240-59.

6. Watson I, Buchanan J, Campbell I, Briggs C. Fragmented futures: new challenges in working life. Sydney: Federation Press, 2003.

7. Australian Centre for Industrial Relations Research and Training. Australia at work. Sydney: Prentice Hall, 1999.

8. Australian Bureau of Statistics. Australian Social Trends 2006. Canberra: ABS, 2006.

9. Green F. Demanding work. Princeton, NJ: Princeton University Press, 2006.

10. Houtman I. Work-related stress. European Foundation for Improvement of Living and Working Conditions, 2005.
11. Cass B. Employment time and family time: the intersections of labour market transformations and family responsibilities in Australia. In: Callus R, Lansbury R, editors. Working futures: the changing nature of work and employment relations in Australia. Leichhardt: Federation Press, 2002.

12. Organisation for Economic Co-operation and Development. Babies and bosses: reconciling work and family life: Paris: OECD, 2002.

13. Jacobs J, Gerson K. The time divide. Cambridge, MA: Harvard University Press, 2004.

14. Brownson RC, Boehmer TK, Luke DA. Declining rates of physical activity in the United States: what are the contributors? Annu Rev Public Health 2005; 26: 421-43. doi:10.1146/annurev.publhealth.26.021304.144437

15. Bittman M, Craig L. The effect of children on adults'time-use: an analysis of incremental time costs of children in Australia. SPRC Discussion Paper No.143. Sydney: Social Policy Research Centre, UNSW, 2005.

16. Sayer L, Bianchi S, Robinson J. Are Parents Investing Less in Children? Trends in Mothers' and Fathers' Time with Children. Am J Sociol 2004; 110(1): 1-43. doi:10.1086/386270

17. Banwell C, Hinde S, Dixon J, Sibthorpe B. Reflections on expert consensus: a case study of the social trends contributing to obesity. Eur J Public Health 2005; 15(6): 564-8. doi:10.1093/eurpub/cki034

18. Sherwood NE, Jeffery RW. The behavioral determinants of exercise: implications for physical activity interventions. Annu Rev Nutr 2000; 20: 21-44. doi:10.1146/annurev.nutr.20.1.21

19. Ball K, Crawford D, Warren N. How feasible are healthy eating and physical activity for young women? Public Health Nutr 2004; 7(3): 433-41. doi:10.1079/PHN2003541

20. Lappalainen R, Saba A, Holm L, Mykkanen H, Gibney MJ, Moles A. Difficulties in trying to eat healthier: descriptive analysis of perceived barriers for healthy eating. Eur J Clin Nutr 1997; 51(Suppl 2): S36-40.

21. Wardman M. Public transport values of time. Transp Policy 2004; 11(4): 363-77. doi:10.1016/j.tranpol.2004.05.001

22. Australian Bureau of Statistics. Population Projections, Australia 2004 to 2101. Canberra: ABS, 2006.

23. Boyle D. Sustainability and social assets: the potential of time banks and co-production. Time Banks UK, 2005. At http://www.timebanks.org/documents/GrassrootsFoundation.pdf, accessed 23 January, 2007

24. Schafer A, Victor DG. The future mobility of the world population. Transport Res A-Pol 2000; 34: 171-205.

25. Mokhtarian PL, Chen C. TTB or not TTB, that is the question: a review and analysis of the empirical literature on travel time (and money) budgets. Transport Res A-Pol 2004; 38: 643-75. 